\title{
Virus-Induced LeSPL-CNR Silencing Inhibits Fruit Ripening in Tomato
}

\author{
Tongfei Lai ${ }^{1, \uparrow}$, Ying Wang ${ }^{1, \dagger}$, Ting Zhou ${ }^{1}$, Fengling Mei ${ }^{1}$, Pengcheng Zhang ${ }^{1}$, Yingying Zhou ${ }^{1}$, Nongnong Shi ${ }^{1}$ \& \\ Yiguo Hong ${ }^{1,2}$ \\ ${ }^{1}$ Research Centre for Plant RNA Signaling, College of Life and Environmental Sciences, Hangzhou Normal \\ University, Hangzhou, China \\ ${ }^{2}$ Warwick-Hangzhou RNA Signaling Joint Laboratory, School of Life Sciences, University of Warwick, \\ Coventry, UK
}

Correspondence: Yiguo Hong, Research Centre for Plant RNA Signaling, College of Life and Environmental Sciences, Hangzhou Normal University, Hangzhou 310036, China. Tel: 86-571-2886-6065. E-mail: yiguo.hong@hzun.edu.cn; yiguo.hong@warwick.ac.uk

${ }^{\dagger}$ These authors equally contributed to this work.

Received: April 1, 2015 Accepted: May 7, 2015 Online Published: June 15, 2015

doi:10.5539/jas.v7n7p184 URL: http://dx.doi.org/10.5539/jas.v7n7p184

\begin{abstract}
Fruit ripening is a developmentally and genetically programmed process. In tomato (Solanum lycopersicum), ripening determines fruit quality, commodity value, shelf life and many important attributes. To understand this intricate process and its underpinning mechanism, an efficient and effective approach for screening and functional analysis of ripening-associated genes (RAGs) is required. Virus-induced gene silencing (VIGS) is a powerful reverse genetics tool for uncovering gene functions in plants. VIGS has been exploited to investigate roles of RAGs in tomato ripening. However in most cases, virus-induced RAG silencing is only assessed and correlated with the chromatic change of fruits. Here we report that silencing of LeSPL-CNR through a Potato virus $X$-based VIGS inhibited fruit ripening and led to development of non-ripening sectors in Ailsa Craig (AC) tomatoes. Non-ripening sectors remained firmer and possessed greater relative electric conductivity and acidity as well as a higher amount of chlorophyll, but a lower quantity of anthocyanin. VIGS of LeSPL-CNR also affects expression of other key RAGs and genes associated with biogenesis of ripening hormone ethylene. These findings indicate that $\mathrm{AC}$ fruits undergoing VIGS of LeSPL-CNR phenocopied physical, physiological, agrochemical, biochemical and molecular characteristics of the Colourless non-ripening epimutant. Thus, the overall phenotypical changes from visual appearance to RAG expression caused by LeSPL-CNR silencing reaffirm the great usefulness of VIGS to reveal biological functions of genes crucial in tomato ripening and fruit quality.
\end{abstract}

Keywords: tomato fruit ripening, virus-induced gene silencing, LeSPL-CNR, ethylene, transcription factor

\section{Introduction}

Fruit ripening is a developmentally and genetically programmed process which undergoes a series of physical, physiological, biochemical and agrochemical changes. For instance fruit colours are affected by accumulation or degradation of certain pigments such as carotenoids, anthocyanins and chlorophylls. Textures and softening are associated with cell wall metabolism and cell turgor. Flavor and nutrient compositions are influenced by metabolic contents of sugars, vitamins, acids and volatiles in a diverse array of tastes and fragrances (Seymour et al., 2013). Ripening determines many important fruit characteristics including quality attributes, shelf-life and commodity values of economic and nutritional importance. It is thus important to understand how fruit ripening is controlled and regulated at the genetic and molecular levels.

Tomato (Solanum lycopersicum) has been emerged as an ideal model plant to elucidate the biological mechanisms underpinning the complex of fruit ripening (Gapper et al., 2013; The Tomato Genome Consortium, 2012). This is being progressively achieved through a range of forward genetics approaches including mutagenesis, screening mutants and RNAi (Radhamony et al., 2005, Agrawal et al., 2003; Smith et al., 2000). These technologies are extremely useful. However they are time-consuming and often involve labour-intensive transformation. On the other hand, virus-induced gene silencing (VIGS) has recently become an attractive and 
powerful reverse-genetics tool for plant functional genomics (Senthil-Kumar \& Mysore, 2011; Becker \& Lange, 2010). In tomato, several RNA and DNA viruses including Tobacco rattle virus, Beet curly top virus, Tomato yellow leaf curl China virus DNA $\beta$ and Apple latent spherical virus have been modified and used to silence genes associated with plant development and fruit ripening (Salu et al., 2012; Golenberg et al., 2009; Igarashi et al., 2009; Cai et al., 2007; Liu et al., 2002). In our laboratory, we have engineered a Potato virus X (PVX)-based vector (Lico et al., 2006; Faivre-Rampant et al., 2004; Dalmay et al., 2000; Chapman et al., 1992) for gene complementation or VIGS to investigate tomato organogenesis and fruit ripening (Kong et al., 2013; Zhou et al., 2012; Lin et al., 2008; Manning et al., 2006). However, in most cases, virus-induced silencing of ripening-associated genes (RAGs) is only examined and correlated with chromatic changes of fruits.

In this study, we further test the usefulness of VIGS for analysis of gene functions in tomato fruit ripening. We used the PVX-based VIGS to silence LeSPL-CNR, a key transcription factor gene in the transcriptional network for control of fruit ripening in tomato (Chen et al., 2015a; Chen et al., 2015b; Manning et al., 2006). We then assessed the impact of LeSPL-CNR silencing on physical appearance of fruits and physiological and agrochemical characteristics as well as on links between these phenotypical alternations and changes of key ripening gene expression. Our results demonstrate that change of tomato colours is a valid mark to reflect the impact of VIGS on ripening although an overall assessment of phenotypical alternations would ensure to validate the genotype-phenotype link in tomato ripening and fruit quality.

\section{Material and Methods}

\subsection{Plant Materials and Growth Conditions}

Tomato (Solanum lycopersicum cv. Ailsa Craig (AC) and the Colourless non-ripening (Cnr) mutant) and tobacco (Nicotiana benthamiana) were grown in insect-free glasshouses at $25{ }^{\circ} \mathrm{C}$ and $80 \%$ humidity with a photoperiod of $16 \mathrm{~h}$ day $/ 8 \mathrm{~h}$ night. Tomato flowers were tagged at anthesis. Fruit development and ripening stages were recorded as days post anthesis (DPA).

\subsection{Construction of the VIGS Vector PVX/mLeSPL-CNR}

Total RNA was extracted from AC fruits at breaker (38-40 DPA) using an RNeasy Plant Mini Kit (Qiagen, Germany). $2 \mu \mathrm{g}$ of RNA were used for synthesis of the first-strand cDNA using a Fast Quant RT Kit (Tiangen Biotech, China). The non-sense mutant $L e S P L-C N R$ gene ( $m L e S P L-C N R$, a stop codon was introduced to replace the start codon) was amplified by Primerstar HS DNA polymerase (Takara, Japan) using a pair of primers (Appendix 1) in an S1000 thermal cycler (Bio-Rad, USA). The resultant PCR products were digested with ClaI/EagI (NEB, USA) and cloned into the PVX vector to generate PVX/mLeSPL-CNR (Chen et al., 2015a; van Wezel et al., 2002). This construct was confirmed by nucleotide sequencing using a pair of PVX sequencing primers (Appendix 1).

\subsection{In vitro Transcription and VIGS}

The PVX or PVX/mLeSPL-CNR plasmid DNA was linearized with SpeI (NEB, USA) and purified by a High Pure PCR Product Purification kit (Roche, USA). The linearized plasmids were resuspended in water supplemented with 1 unit $\mu \mathrm{L}^{-1}$ RNasin Ribonuclease Inhibitor (Promega, USA). Riboprobe in vitro Transcription Systems (Promega, USA) was used to synthesize single-stranded PVX or PVX/mLeSPL-CNR RNA transcripts as previously described (Chen et al., 2015a; Zhou et al., 2012). Young leaves of N. benthamiana were mechanically inoculated with viral RNA transcripts. At 10 days post inoculation, systemically infected leaves were collected, freeze-dried and stored at $-80^{\circ} \mathrm{C}$ until use.

VIGS was performed as previously described (Manning et al., 2006). Briefly, approximately $0.1 \mathrm{~g}$ freeze-dried leaf tissues were ground in $1 \mathrm{~mL}$ TE buffer ( $\mathrm{pH}$ 7.5). Leaf saps were needle-injected into the carpopodium of immature tomato fruits (about 15 DPA). At 5 days after breaker, fruits with obvious unripe sectors were photographed and harvested for subsequent examinations.

\subsection{Determination of Fruit Quality Parameters}

(1) Fruit firmness was determined by a Texturanalysator TMS-Pro ILC Load Cells 500N (Food Technology Corporation, USA) equipped with a needle probes (TMS $1 \mathrm{~mm}$ st. steel, $9-10^{\circ}$ taper). Value load range was set as $5 \mathrm{~mm}$ and the peak load was recorded.

(2) Soluble solids content (SSC) was determined using an Abbe Refractometer (10481 S/N, USA).

(3) Titratable acidity (TA) was analyzed by titration with $0.01 \mathrm{~mol} \mathrm{~L}^{-1} \mathrm{NaOH}$ up to $\mathrm{pH} 8.3$ in $25 \mathrm{~mL}$ of diluted juice from $3 \mathrm{~g}$ fruit flesh.

(4) Relative electric conductivity was measured using a conductivity meter Five Easy plus EF30 (METTLER 
TOLEDO, USA). Fruit fleshes (about $3 \mathrm{~g}$ ) were washed three times in deionized water, and put into a $50 \mathrm{~mL}$ conical flask containing $30 \mathrm{~mL}$ deionized water. After $3 \mathrm{~h}$ of incubation at $25^{\circ} \mathrm{C}$, the initial electrolyte leakage was determined (D1). The solution was then placed in a water bath at $95{ }^{\circ} \mathrm{C}$ for $30 \mathrm{~min}$ before the final conductivity (total electrolyte leakage, D2) was measured. Relative electric conductivity $=[(\mathrm{D} 2-\mathrm{D} 1) / \mathrm{D} 2] \times$ $100 \%$ (Lai et al., 2011).

(5) Chlorophyll content was determined according the method described by Wang et al. (2009) with slight modification. Samples (about $3 \mathrm{~g}$ ) were grounded in liquid nitrogen and rapidly transferred to a tube with $25 \mathrm{~mL}$ $80 \%$ acetone. After mixing, the acetone-phase was collected after centrifugation $(10,000 \mathrm{~g}, 10 \mathrm{~min})$ at room temperature. Then, absorbance at 645 and $663 \mathrm{~nm}$ was recorded for determination of chlorophyll a and chlorophyll b using a Smart Sprec Plus spectrophotometer (Bio-Rad, USA). Chlorophyll concentration $=8.33 \times$ $\left(8.02 \times \mathrm{OD}_{663}+20.20 \times \mathrm{OD}_{645}\right)\left(\mu \mathrm{g} \mathrm{g}^{-1} \mathrm{FW}\right)$.

(6) The anthocyanin was extracted using the method reported by Zhang et al. (2014) with slight modification. About $2 \mathrm{~g}$ samples were grounded in liquid nitrogen and transferred to a $50 \mathrm{~mL}$ conical flask with $25 \mathrm{~mL}$ methanol containing $0.1 \mathrm{~mol} \mathrm{~L}^{-1}$ hydrochloric acid. The conical flask was sealed by parafilm and placed in dark for $24 \mathrm{~h}$. Then, the suspensions were centrifuged to remove fruit residues, protein and polysaccharide sediments. Absorbance was measured on a spectrophotometer. The relative content of anthocyanin was represented by absorbance $\mathrm{g}^{-1} \mathrm{FW}$ at $525 \mathrm{~nm}$.

\section{5 qRT-PCR Analysis}

The total RNA extraction and the first-strand cDNA synthesis were described as above. Quantitative real-time PCR (qRT-PCR) was performed using $2 \times$ Ultra SYBR mixture (CW Bio, China) in a CFX96- real Time System (Bio-Rad, USA). Primer pairs for quantitative RT-PCR of the selected genes were shown in Appendix 1. The PCR conditions were as follows: $95^{\circ} \mathrm{C}$ for $10 \mathrm{~min}$, followed by 40 circles of $95{ }^{\circ} \mathrm{C}$ for $15 \mathrm{~s}, 58{ }^{\circ} \mathrm{C}$ for $15 \mathrm{~s}$ and $72{ }^{\circ} \mathrm{C}$ for $20 \mathrm{~s}$. The change in fluorescence of SYBR Green in every cycle was monitored by the system software, and the threshold cycle $(C t)$ over the background was calculated for each reaction. Samples were normalized using $18 \mathrm{~S}$ rRNA and the relative expression levels were measured using the $2^{(-\triangle \mathrm{Ct})}$ analysis method (Zhou et al., 2012).

\subsection{Statistical Analysis}

Data were collected from at least three independent experiments and were analyzed software (SPSS Inc., Chicago, IL, USA). Analysis of variance (ANOVA) was used to compare more than two means, and Duncan's multiple range tests were used for means separations. Differences at $P \leq 0.05$ were considered to be significant.

\section{Results}

\subsection{Expression Profiles of LeSPL-CNR in Wild-Type AC and Cnr Mutant Fruits}

In plants, VIGS often occurs during virus infection and the occurrence of VIGS usually takes 2-3 weeks after initial inoculation of plant tissues with a VIGS vector. Silencing, once induced by a VIGS vector, maintains afterwards. Therefore it is important to determine when VIGS vector should be introduced into plant tissues and cells, which depends on timing profiles of target gene expression in plants. In order to induce efficient VIGS of LeSPL-CNR, we first analyzed levels of LeSPL-CNR mRNA at different developmental stages of AC fruits by qRT-PCR. We found that a lower level of transcripts was detected at the immature green (IMG) stage (approximately $15 \mathrm{DPA}$ ). Then expression of LeSPL-CNR increased gradually at mature green (MG, approximately $30 \mathrm{DPA})$, reached a peak at the breaker stage (38-40 DPA), and followed by a rapid decline when $\mathrm{AC}$ fruits started to show ripe red $(\mathrm{B}+5)$ and ripened fully $(\mathrm{B}+10$, Figure 1). However, in $\mathrm{Cnr}$ mutant fruits, expression levels of LeSPL-CNR reduced substantially and remained a very low level throughout all the developmental stages (Figure 1). These results suggest that VIGS vector for silencing LeSPL-CNR should be delivered into AC fruits around the IMG stage. 


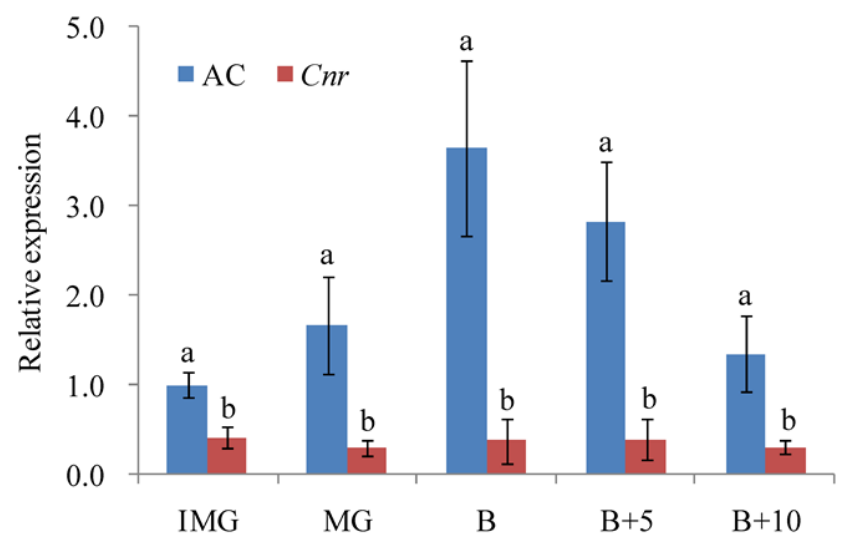

Figure 1. Differential and developmental expression of LeSPL-CNR in Ailsa Craig (AC) and $\mathrm{Cnr}$ epimutant fruits

Note. The relative expression levels were compared against that in $\mathrm{AC}$ fruit at immature green stage. IMG, Immature green; MG, Mature green; $\mathrm{B}$, Breaker; $\mathrm{B}+5,5$ days after breaker; $\mathrm{B}+10,10$ days after breaker. Bars represent standard deviation of the means. For a particular developmental stage, lowercase letters $\mathrm{a}$ and $\mathrm{b}$ indicate significant differences at $P<0.05$

\subsection{Large-Scale Production of PVX/mLeSPL-CNR}

RNA transcripts produced in vitro transcription from linearized PVX/mLeSPL-CNR (Figure 2A) could be directly used for VIGS experiments in tomato fruits. However, the quantity of the recombinant viral RNA produced in this way is limited and cost ineffective. To overcome these disadvantages, we first generated a small amount of PVX and PVX/mLeSPL-CNR RNAs by in vitro transcription (Figure 2B). These viral RNAs were used to inoculate young leaves of $N$. benthamiana. At 7-10 days post inoculation (dpi), plants developed obvious chlorotic lesions on inoculated leaves and curling, mosaic and chlorosis on systemically infected leaves (Figure 2C). Consistent with viral symptom development, accumulation of the recombinant viral RNAs was further confirmed by RT-PCR, followed by direct sequencing of the resultant RT-PCR products. The insert of $m L e S P L-C N R$ RNA in PVX/mLeSPL-CNR was maintained during the course of infection (Figures 2D and 2E). Young leaves with obvious viral symptoms were collected and used for VIGS experiments. Saps of a single leaf (approximately 0.5 grams) could be used for approximately 100 tomato fruits in VIGS experiments. 


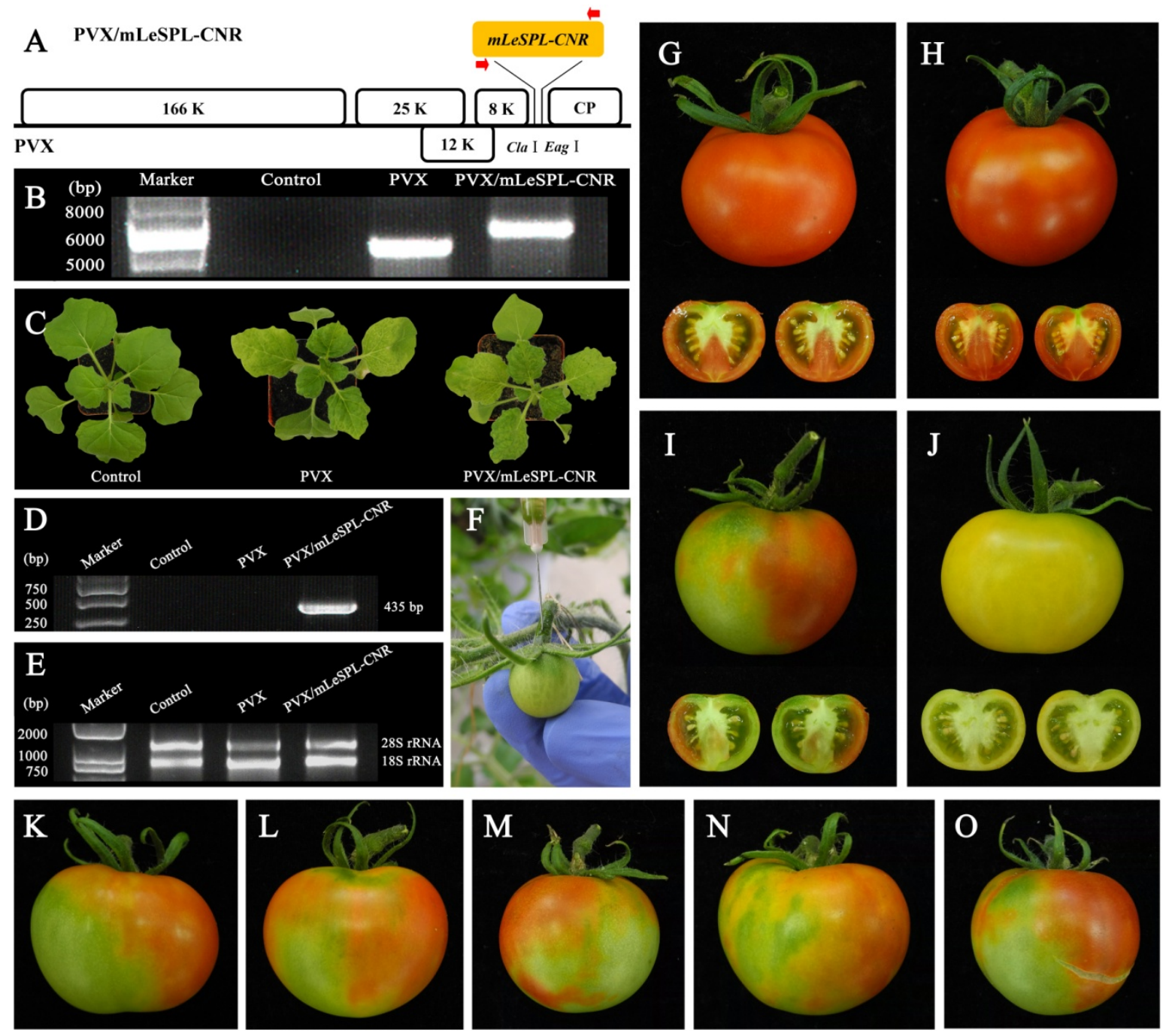

Figure 2. VIGS of LeSPL-CNR inhibits fruit ripening

Note. (A) A schematic representation of the VIGS vector PVX/mLeSPL-CNR. The $m L e S P L-C N R$ was cloned into the ClaI/EagI sites of the PVX vector (van Wezel et al., 2002). RNA-dependent RNA polymerase (166 kDa), three viral movement proteins $(25,12$ and $8 \mathrm{kDa})$ encoded by the triple-gene block and coat protein $(\mathrm{CP})$ are indicated. (B) Analysis of in vitro transcription RNA products for PVX (approximately $6.9 \mathrm{~kb}$ ) and PVX/mLeSPL-CNR (approximately $7.34 \mathrm{~kb}$ ). (C) Infection of $N$. benthamiana with PVX or $\mathrm{PVX} / \mathrm{mLeSPL}-\mathrm{CNR}$ through mechanical inoculation. Plants were mock-inoculated of with $\mathrm{H}_{2} \mathrm{O}$ as negative controls. Photographs were taken at 10 days post inoculation. (D, E) RT-PCR detection of PVX/mLeSPL-CNR in infected leaves of $N$. benthamiana (D). An equal amount of total RNA was used for RT-PCR assays of each sample (E). Positions of the specific RT-PCR product as well as $28 \mathrm{~S}$ and $18 \mathrm{~S}$ RNA are indicated. (F) Needle-injection of leaf saps onto the carpopodium of a tomato fruit at the immature green stage for VIGS. (G-J) Ripening phenotypes of wild-type AC fruit $(\mathrm{G})$, AC fruit injected with PVX $(\mathrm{H})$, AC fruit injected with PVX/mLeSPL-CNR (I) and a Cnr mutant fruit (J) at 45 day post anthesis. Fruits are bi-dissected to show internal ripe and/or non-ripening tissues. (K-O) AC fruits injected with PVX/mLeSPL-CNR developed non-ripening sectors with $30-55 \%$ of fruit surface arena. Photographs were taken at $\mathrm{B}+5$.

\subsection{Delivery of PVX/LeSPL-CNR into Tomato Blocks Fruit Ripening}

Through the carpopodium, immature green fruits (15-20 DPA) were needle-injected with leaf saps from $N$. benthamiana plants containing with PVX (empty VIGS vector as negative control) or PVX/mLeSPL-CNR RNAs (Figure 2F). At 38-40 DPA, all fruits mock-injected or injected with PVX showed colour breaker (B) where green started to turn tannish-yellow, pink, or red. At 5 days after breaker $(\mathrm{B}+5)$, these control fruits ripened and appeared red (Figures $2 \mathrm{G}$ and $2 \mathrm{H}$ ). However, approximately $15 \%$ of the fruits injected with 
PVX/mLeSPL-CNR developed distinct non-ripening green sectors which occupied 30-55\% of fruit surfaces (Figures 2I, 2K-2O). The non-ripening sectors eventually mimicked the phenotypes of $\mathrm{Cnr}$ mutant fruits (Figure 2J). These findings demonstrate that PVX/mLeSPL-CNR is capable of triggering VIGS to block fruit ripening.

In addition to visual changes of physical appearance of fruit colours, we further analyzed and compared important physiological and agrochemical characteristics associated with the non-ripening green and red-ripe sectors of these VIGS fruits (Figure 3). In general, ripe fruits injected with PVX and the red sectors of fruits injected with PVX/mLeSPL-CNR possessed very similar ripening attributes. However differences on fruit quality between red and green sectors of fruits injected with PVX/mLeSPL-CNR were significant. Firmness, relative electric conduction, titratable acidity and chlorophyll content were higher (Figures 3A-3C, 3E) and anthocyanin content lower in green than red sectors (Figure 3F). However, the soluble solids contents were almost identical in the whole fruit (Figure 3D). These results indicate that delivery of PVX/mLeSPL-CNR can effectively inhibits fruit ripening and that the colour mark to reflect ripe or non-ripening phenotype is positively correlated with physiological and agrochemical alternations associated with fruit ripening.
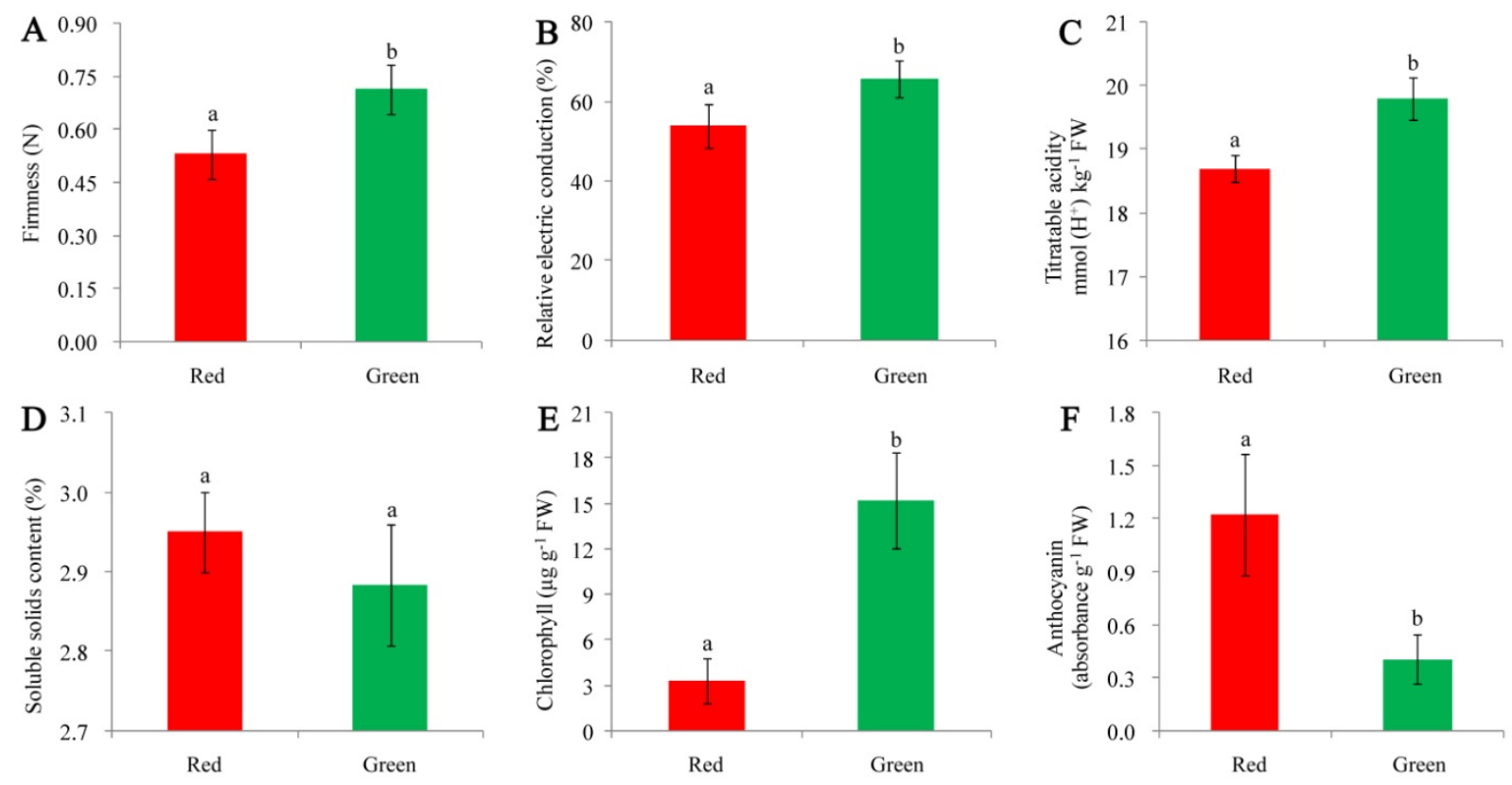

Figure 3. Physiological and agrochemical characteristics of AC fruits undergoing VIGS of LeSPL-CNR silencing fruits at 5 days after breaker

Note. A: firmness; B: relative electric conduction; C: titratable acidity; D: soluble solids content; E: chlorophyll content; F: anthocyanin content. Bars represent standard deviation of the means. Lowercase letters a and b indicated significant differences at $P<0.05$ between red ripe (Red) and green non-ripening (Green) sectors of the AC fruit injected with PVX/mLeSPL-CNR.

\subsection{Effects of PVX Mediated LeSPL-CNR Silencing on Expression of Key RAGs and Ethylene Biosynthesis Genes}

VIGS effectiveness was analyzed at the transcript level by monitoring LeSPL-CNR mRNA accumulation by qRT-PCR. We found that the expression of $L e S P L-C N R$ in green non-ripening sectors was down-regulated and only about $30-50 \%$ of that in red ripe sectors (Figure 4A), consistent with our previous analysis (Manning et al., 2006). Furthermore, it is known that a number of transcription factors (TFs) are required for initiation and promotion of fruit ripening (Karlova et al., 2014). These TFs are believed to regulate, directly and indirectly, expression of numerous downstream ripening-related genes associated with ethylene-mediated and independent ripening regulatory pathways. Therefore, expression levels of these key ripening TFs were assessed in the LeSPL-CNR silenced AC fruits. We found that expression levels of SlAP2a, LeHB1, SIMADS1, SIMYB, LeNOR and SITAGL1 were higher in green than red sectors. No notable differences were detected in the expression levels of LeTDR4 and LeMADS-RIN among all the samples (Figures 4B-4I). On the other hand, ethylene production is an important parameter for typical respiration climacteric fruits. Thus expression of ethylene biosynthesis genes 
was also evaluated by qRT-PCR. The results indicated that expression levels of LeACS1, LeACS3, LeACS4, LeACS6, LeACO3 and LeACO4 were higher in green than red sectors of fruits injected with PVX/mLeSPL-CNR. Interestingly, the mRNA levels of LeACS2 and LeACO1 were lower in green than red sectors. Meanwhile, LeACO2 level were nearly identical in all samples (Figures 5A-5I).
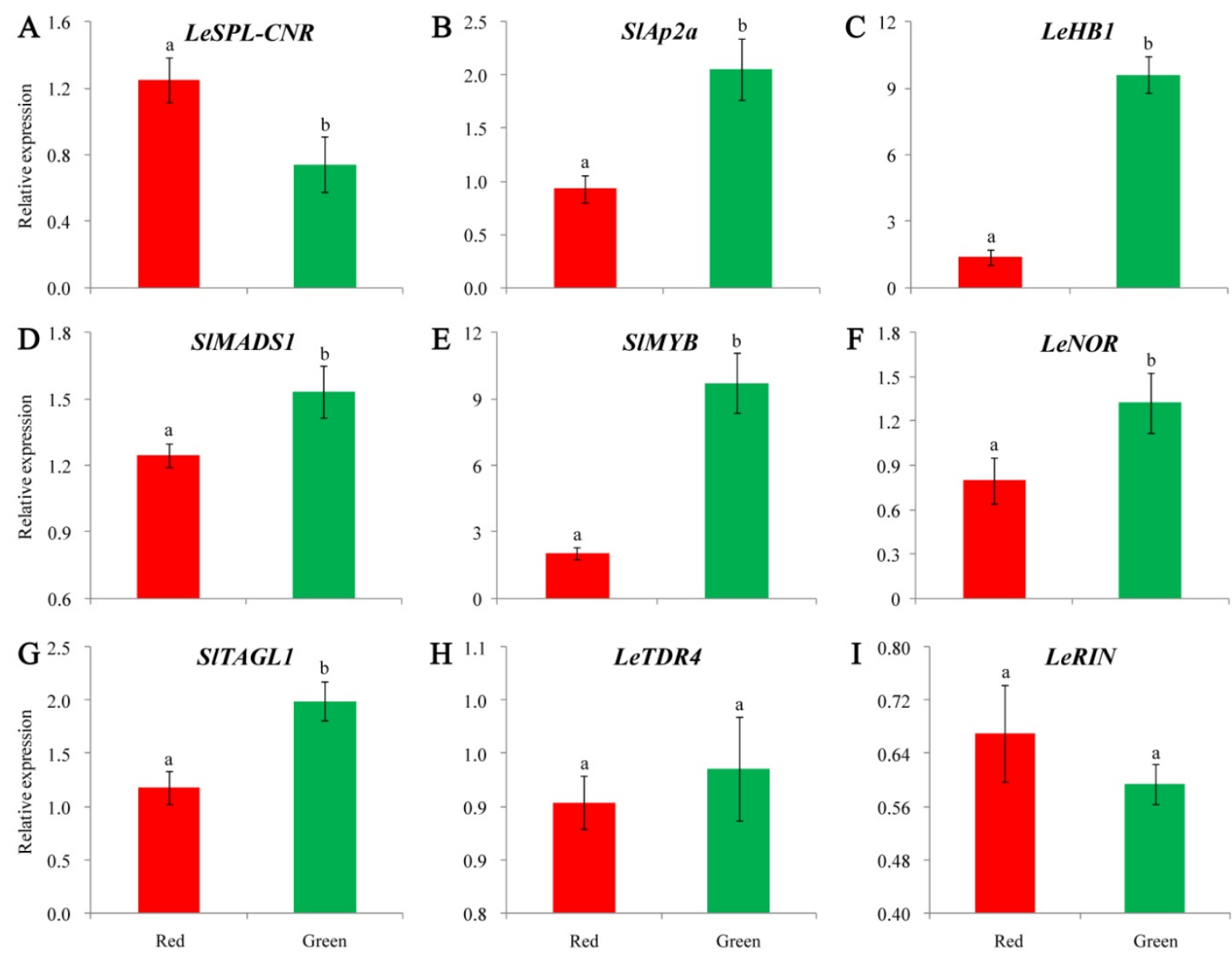

Figure 4. Expression of key ripening-associated transcription factor genes in $\mathrm{AC}$ fruits injected with $\mathrm{PVX} / \mathrm{mLeSPL}-\mathrm{CNR}$ at 5 days after breaker

Note. The relative expression levels of each of genes including LeSPL-CNR (A), SlAP2a (B), LeHB1 (C), SIMADS1 (D), SIMYB (E), LeNOR (F), SITAGL1 (G), LeTDR4 (H) and LeMADS-RIN (LeRIN, I) were compared against those in tomato fruits injected with PVX. Bars represent standard deviation of the means. Lowercase letters a and $\mathrm{b}$ indicate significant differences at $P<0.05$ between red ripe (Red) and green non-ripening (Green) sectors of the AC fruit injected with PVX/mLeSPL-CNR.

\section{Discussion}

LeSPL-CNR is mapped in the euchromatin region on the long arm of tomato chromosome 2 closed to the CT277 marker, and encodes a transcription factor of the Squamosa Promoter Binding-like Protein. The Cnr epimutation resulted from hypermethylation in a 286 bp region of the LeSPL-CNR promoter inhibits normal ripening and produces a severe phenotype whereby fruits develop a colorless mealy pericarp (Chen et al., 2015b; Manning et al., 2006; Eriksson et al., 2004; Orfila et al., 2001; Thompson et al., 1999). Suppression of LeSPL-CNR in wild-type AC fruits by VIGS can block ripening and lead to formation of non-ripening sectors. The colour change in VIGS fruits is consistent with physiological and agrochemical alternations with respect of firmness, titratable acidity, chlorophyll and anthocyanin content as well as the relative electric conduction.

Ethylene plays a critical role in tomato development and fruit ripening. The biosynthetic pathway of ethylene includes two key enzymes. S-adenosylmethionine is converted to 1-aminocyclopropane-1-carboxylate (ACC) by ACC synthase (ACS). ACC is subsequently converted to ethylene by ACC oxidase (ACO) (Cara \& Giovannoni, 
2008). There are at least 8 characterized $A C S$ genes in tomato, but all ethylene biogenesis is largely driven by LeACS2 and LeACS4 (Klee \& Giovannoni, 2011). Interestingly, silencing of LeSPL-CNR imposes an opposite impact on mRNA levels of LeACS2 and LeACS4 although both genes are down-regulated in the Cnr epimutant fruits at 45 DPA (Figure 5). On the other hand, ACOs are also a multigene family in tomato although ACO activity is generally not the rate-limiting factor in ethylene production (Barry et al., 1996). Nevertheless, LeACO1 plays a major role in ripening regulation and expression of this gene is down-regulated in the LeSPL-CNR silenced AC fruits. Taken together, LeSPL-CNR silencing disturbs the expression of ethylene biosynthetic genes that are associated with fruit ripening.
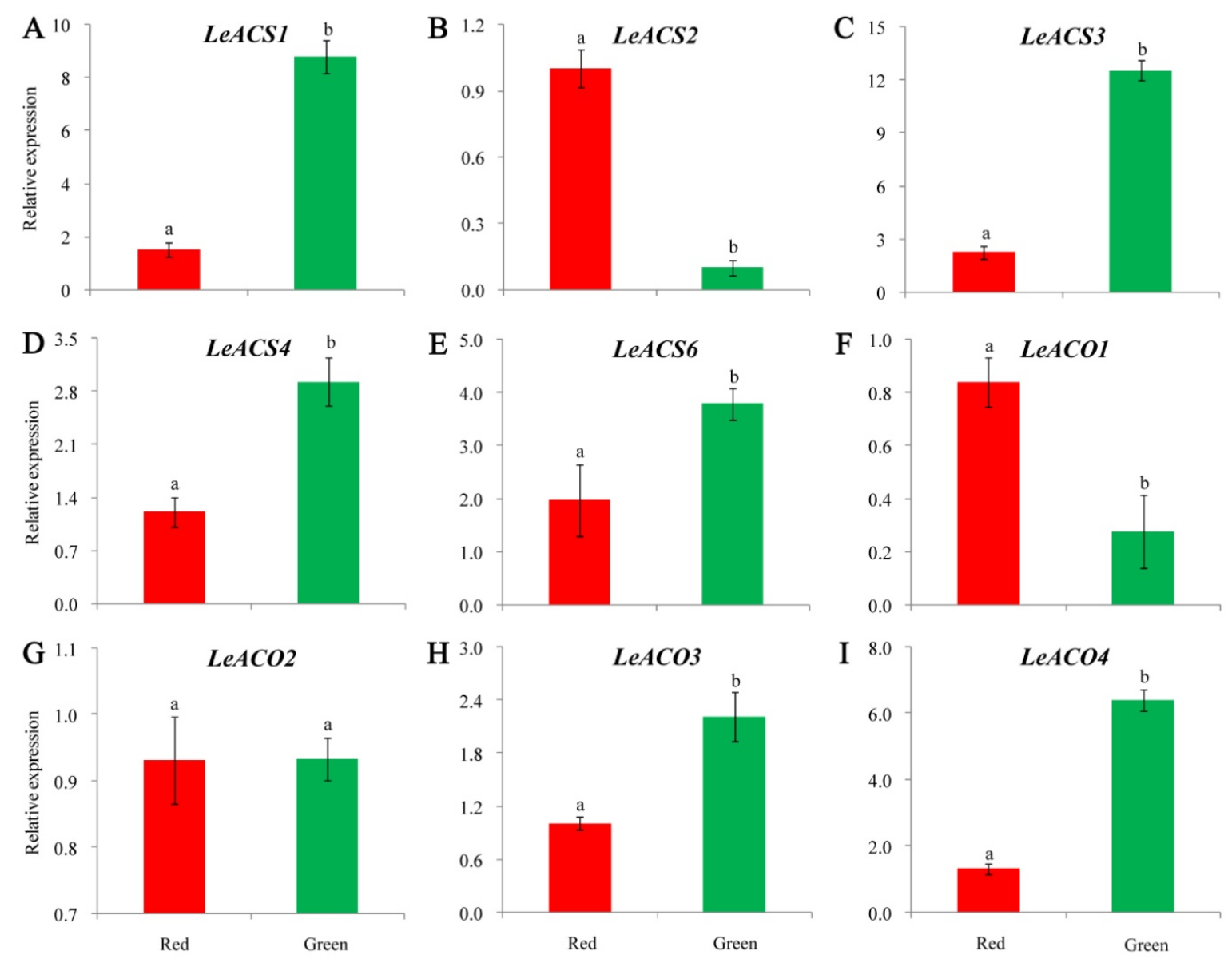

Figure 5. Expression of genes related to ethylene biosynthesis in AC fruits injected with PVX/mLeSPL-CNR at 5 days after breaker

Note. The relative expression levels of each of genes including LeACS1 (A), LeACS2 (B), LeACS3 (C), LeACS4 (D), LeACS6 (E), LeACO1 (F), LeACO2 (G), LeACO3 (H) and LeACO4 (I) were compared against those in tomato fruits injected with PVX. Bars represent standard deviation of the means. Lowercase letters a and $b$ indicate significant differences at $P<0.05$ between red ripe (Red) and green non-ripening (Green) sectors of the AC fruit injected with PVX/mLeSPL-CNR.

Regulation of fruit ripening in tomato involves not only phytohormone signaling pathway but also TFs (Rohrmann et al., 2012). Several TF genes including SlAP2a, LeHB1, SlMADS1, SIMYB, SITAGL1 and LeTDR4 have recently been found to play significant roles in fruit ripening in tomato (Wang et al., 2014; Dong et al., 2013; Ballester et al., 2010; Vrebalov et al., 2009; Lin et al., 2008). These TFs, acting either in concert or independently, are believed to form a sophisticated transcriptional regulatory network to regulate ripening (Fujisawa et al., 2012; Zhou et al., 2012). For instance, LeTDR4 and LeMADS-RIN may be located at the upstream of $L e S P L-C N R$ in transcriptional cascade and their expression may not be influenced by the expression change of LeSPL-CNR (Fujisawa et al., 2014). This idea is consistent with our finding (Figure 4). On the other 
hand, LeSPL-CNR negatively regulates SlAP2a in a feedback loop in the control of tomato fruit ripening (Chung et al., 2010; Karlova et al., 2011), it is thus not unexpected that silencing LeSPL-CNR caused a significant up-regulation of SIAP2a. Our results also suggest that LeSPL-CNR may involve down-regulation other ripening TFs (Figure 4). Therefore our data support existence of a TF network in the control of tomato fruit ripening (Chen et al., 2015a; 2015b).

\section{Acknowledgements}

We are indebted to David Baulcombe for his kind gift of the original PVX vector. This work was supported in part by a Pandeng Programme from Hangzhou Normal University (201108), an Innovative Grant for Science Excellence from the Hangzhou City Education Bureau China, a grant from the National Natural Science Foundation of China (NSFC31370180) and an International Collaboration Grant from Hangzhou Normal University to YH. We also thank NSFC and the Zhejiang Provincial Natural Science Foundation for grants (NSFC31401926, LQ12C02005, LQ14C200004 and LY14C010005) to support our laboratories.

\section{References}

Agrawal, N., Dasaradhi, P. V., Mohmmed, A. N., Malhotra, P., Bhatnagar, R. K., \& Mukherjee, S. K. (2003). RNA interference: Biology, mechanism, and applications. Microbiology and Molecular Biology Reviews, 67, 657-685. http://dx.doi.org/10.1128/MMBR.67.4.657-685.2003

Ballester, A. R., Molthoff, J., Vos, R., Hekkert, B. L., Orzaez, D., Fernández-Moreno, J. P., ... Báovy, A. (2010). Biochemical and molecular analysis of pink tomatoes: Deregulated expression of the gene encoding transcription factor SIMYB12 leads to pink tomato fruit color. Plant Physiology, 152, 71-84. http://dx.doi.org/10.1104/pp.109.147322

Barry, C. S., Blume, B., Bouzayen, M., Cooper, W., Hamilton, A. J., \& Grierson, D. (1996). Differential expression of the 1-aminocyclopropane-1-caboxylate oxidase gene family of tomato. The Plant Journal, 9(4), 525-535. http://dx.doi.org/10.1046/j.1365-313X.1996.09040525.x

Becker, A., \& Lange, M. (2010). VIGS-genomics goes functional. Trends in Plant Science, 15, 1-4. http://dx.doi.org/10.1016/j.tplants.2009.09.002

Cai, X. Z., Wang, C. C., Xu, Y. P., Xu, Q. F., Zheng, Z., \& Zhou X. P. (2007). Efficient gene silencing induction in tomato by a viral satellite DNA vector. Virus Research, 125, 169-175. http://dx.doi.org/10.1016/j.virusres.2006.12.016

Cara, B., \& Giovannoni, J. J. (2008). Molecular biology of ethylene during tomato fruit development and maturation. Plant Science, 175, 106-113. http://dx.doi.org/10.1016/j.plantsci.2008.03.021

Chapman, S., Kavanagh T., \& Baulcombe, D. (1992). Potato virus X as a vector for gene expression in plants. The Plant Journal, 2, 549-557. http://dx.doi.org/10.1046/j.1365-313X.1992.t01-24-00999.X

Chen, W., Kong, J., Lai, T., Manning, K., Wu, C., Wang, Y., ... Hong, Y. (2015a). Tuning LeSPL-CNR expression by SlymiR157 affects tomato fruit ripening. Scientific Reports, 5, 7852. http://dx.doi.org/10.1038/srep07852

Chen, W., Kong, J., Qin, C., Yu, S., Tan, J., Chen, Y., ... Hong, Y. (2015b) Requirement of CHROMOMETHYLASE3 for somatic inheritance of the spontaneous tomato epimutation Colourless non-ripening. Scientific Reports, 5, 9192. http://dx.doi.org/10.1038/srep09192

Chung, M., Vrebalov, J., Alba, R., Lee, J., McQuinn, R., Chung, J., ... Giovannoni, J. (2010). A tomato (Solanum lycopersicum) APETALA2/ERF gene, SlAP2a, is a negative regulator of fruit ripening. The Plant Journal, 64, 936-947. http://dx.doi.org/10.1111/j.1365-313X.2010.04384.x

Dalmay, T., Hamilton, A., Mueller, E., \& Baulcombe, D. C. (2000). Potato Virus X amplicons in Arabidopsis mediate genetic and epigenetic gene silencing. The Plant Cell, 12, 369-379. http://dx.doi.org/10.1105/tpc.12.3.369

Dong, T. T., Hu, Z. L., Deng, L., Wang, Y., Zhu, M. K., Zhang, J. L., \& Chen, G. P. (2013). A tomato MADS-box transcription factor, SIMADS1, acts as a negative regulator of fruit ripening. Plant Physiology, 163, 1026-1036. http://dx.doi.org/10.1104/pp.113.224436

Eriksson, E. M., Bovy, A., Manning, K., Harrison, L., Andrews, J., De Silva, J., ... Seymour, G. B. (2004). Effect of the colorless non-ripening mutation on cell wall biochemistry and gene expression during tomato fruit development and ripening. Plant Physiology, 136, 4184-4197. http://dx.doi.org/10.1104/pp.104.045765 
Faivre-Rampant, O., Gilroy, E. M., Hrubikova, K., Hein, I., Millam, S., Loake, G. J., ... Lacomme, C. (2004). Potato virus $X$-induced gene silencing in leaves and tubers of potato. Plant Physiology, 134, 1308-1316. http://dx.doi.org/10.1104/pp.103.037507

Fujisawa, M., Shima, Y., Higuchi, N., Nakano, T., Koyama, Y., Kasumi, T., \& Ito, Y. (2012). Direct targets of the tomato-ripening regulator RIN identified by transcriptome and chromatin immunoprecipitation analyses. Planta, 6, 1107-1122. http://dx.doi.org/10.1007/s00425-011-1561-2

Fujisawa, M., Shima, Y., Nakagawa, H., Kitagawa, M., Kimbara, J., Nakano, T., ... Ito Y. (2014). Transcriptional regulation of fruit ripening by tomato FRUITFULL homologs and associated MADS box proteins. The Plant Cell, 26, 89-101. http://dx.doi.org/10.1105/tpc.113.119453

Gapper, N. E., McQuinn, R. P., \& Giovannoni, J. J. (2013). Molecular and genetic regulation of fruit ripening. Plant Molecular Biology, 82, 575-591. http://dx.doi.org/10.1007/s11103-013-0050-3

Golenberg, E. M., Sather, D. N., Hancock, L. C., Buckley, K. J., Villafranco, N. M., \& Bisaro, D. M. (2009). Development of a gene silencing DNA vector derived from a broad host range geminivirus. Plant Methods, 5, 1-14. http://dx.doi.org/10.1186/1746-4811-5-9

Igarashi, A., Yamagata, K., Sugai, T., Takahashi, Y., Sugawara, E., Tamura, A., ... Yoshikawa, N. (2009). Apple latent spherical virus vectors for reliable and effective virus-induced gene silencing among a broad range of plants including tobacco, tomato, Arabidopsis thaliana, cucurbits, and legumes. Virology, 386, 407-416. http://dx.doi.org/10.1016/j.virol.2009.01.039

Karlova, R., Chapman, N., David, K., Angenent, G. C., Seymour, G. B., \& de Maagd R. A. (2014). Transcriptional control of fleshy fruit development and ripening. Journal of Experimental Botany, 65, 4527-4541. http://dx.doi.org/10.1093/jxb/eru316

Karlova, R., Rosin, F. M., Busscher-Lange, J., Parapunova, V., Do, P. T., Fernie, A. R., ... deMaagd, R. A. (2011). Transcriptome and metabolite profiling show that APETALA2a is a major regulator of tomato fruit ripening. The Plant Cell, 23, 923-941. http://dx.doi.org/10.1105/tpc.110.081273

Klee, H. J., \& Giovannoni, J. J. (2011). Genetics and control of tomato fruit ripening and quality attributes. Annual Review of Genetics, 45, 41-59. http://dx.doi.org/10.1146/annurev-genet-110410-132507

Kong, J., Chen, W., Shen, J., Qin, C., Lai, T., Zhang, P., ... Hong, Y. (2013). Virus-induced gene complementation in tomato. Plant Signaling \& Behavior, e27142. http://dx.doi.org/10.4161/psb.27142

Lai, T., Wang, Y., Li, B., Qin, G., \& Tian, S. (2011). Defense responses of tomato fruit to exogenous nitric oxide during postharvest storage. Postharvest Biology and Technology, 62, 127-132. $\mathrm{http} / / / \mathrm{dx}$.doi.org/10.1016/j.postharvbio.2011.05.011

Lico, C., Capuano, F., Renzone, G., Donini, M., Marusic, C., Scaloni, A., ... Baschieri, S. (2006). Peptide display on potato virus $X$ : molecular features of the coat protein-fused peptide affecting cell-to-cell and phloem movement of chimeric virus particles. Journal of General Virology, 87, 3103-3112. http://dx.doi.org/10.1099/vir.0.82097-0

Lin, Z. F., Hong, Y. G., Yin, M. G., Li, C. Y., Zhang, K., \& Grierson, D. (2008). A tomato HD-Zip homeobox protein, LeHB-1, plays an important role in floral organogenesis and ripening. The Plant Journal, 55, 301-310. http://dx.doi.org/10.1111/j.1365-313X.2008.03505.x

Liu, Y., Schiff, M., \& Dinesh-Kumar, S. P. (2002). Virus-induced gene silencing in tomato. The Plant Journal, 31, 777-786. http://dx.doi.org/10.1046/j.1365-313X.2002.01394.x

Manning, K., Tör, M., Poole, M., Hong, Y. G., Thompson, A. J., King, G. J., ... Seymour, G. B. (2006). A naturally occurring epigenetic mutation in a gene encoding an SBP-box transcription factor inhibits tomato fruit ripening. Nature Genetics, 38, 948-952. http://dx.doi.org/10.1038/ng1841

Orfila, C., Seymour, G. B., Willats, G. T., Huxham, I. M., Jarvis, M. C., Dover, C. J., ... Knox, J. P. (2001). Altered middle lamella homogalacturonan and disrupted deposition of $(1 \rightarrow 5)-\alpha$-L-Aranan in the pericarp of $C n r$, a ripening mutant of tomato. Plant Physiology, 126, 210-221. http://dx.doi.org/10.1104/pp.126.1.210

Radhamony, R. N., Prasad, A. M., \& Srinivasan, R. (2005). T-DNA insertional mutagenesis in Arabidopsis: a tool for functional genomics. Electronic Journal of Biotechnology, $8,1$. http://dx.doi.org/10.2225/vol8-issue1-fulltext-4 
Rohrmann, J., McQuinn, R., Giovannoni, J. J., Fernie, A. R., \& Tohge, T. (2012) Tissue specificity and differential expression of transcription factors in tomato provide hints of unique regulatory networks during fruit ripening. Plant signaling \& behavior, 7, 1639-1647. http://dx.doi.org/10.4161/psb.22264

Senthil-Kumar, M., \& Mysore, K. S. (2011). New dimensions for VIGS in plant functional genomics. Trends in Plant Science, 16, 656-665. http://dx.doi.org/10.1016/j.tplants.2011.08.006

Sahu, P. P., Puranik, S., Khan, M., \& Prasad, M. (2012). Recent advances in tomato functional genomics: utilization of VIGS. Protoplasma, 249, 1017-1027. http://dx.doi.org/10.1007/s00709-012-0421-7

Seymour, G. B., Ostergaard, L., Chapman, N. H., Knapp, S., \& Martin, C. (2013). Fruit development and $\begin{array}{lllll}\text { ripening. Annual Review of Plant } & \text { Biology, }\end{array}$ http://dx.doi.org/10.1146/annurev-arplant-050312-120057

Smith, N. A., Singh, S. P., Wang, M., Stoutjesdijk, P. A., Green, A. G., \& Waterhouse, P. M. (2000). Total $\begin{array}{llll}\text { silencing by intron-spliced hairpin RNAs. Nature, 407, 319-320. } & \text {. }\end{array}$ http://dx.doi.org/10.1016/j.tplants.2011.08.006

The Tomato Genome Consortium. (2012). The tomato genome sequence provides insights into fleshy fruit evolution. Nature, 485, 635-641. http://dx.doi.org/10.1038/nature11119

Thompson, A. J., Tor, M., Barry, C. S., Vrebalov, J., Orfila, C., Jarvis, M. C., ... Seymour, G. B. (1999). Molecular and genetic characterization of a novel pleiotropic tomato-ripening mutant. Plant Physiology, 120, 383-389. http://dx.doi.org/10.1104/pp.120.2.383

van Wezel, R., Dong, X., Liu, H., Tien, P., Stanley, J., \& Hong Y. (2002). Mutation of three cysteine residues in tomato yellow leaf curl virus-China $\mathrm{C} 2$ protein causes dysfunction in pathogenesis and posttranscriptional gene-silencing suppression. Molecular Plant-Microbe Interactions, 15, 203-208. http://dx.doi.org/10.1094/MPMI.2002.15.3.203

Vrebalov, J., Pan, I. L., Arroyo, A. J., McQuinn, R., Chung, M. Y., Poole, M., ... Irish, V. F. (2009). Fleshy fruit expansion and ripening are regulated by the tomato SHATTERPROOF gene TAGL1. The Plant Cell, 21, 3041-3062. http://dx.doi.org/10.1105/tpc.109.066936

Wang, Q., Lai, T. F., Qin, G. Z., \& Tian, S. P. (2009) Response of jujube fruits to exogenous oxalic acid treatment based on proteomic analysis. Plant and Cell Physiology, 50, 230-242. http://dx.doi.org/10.1093/pcp/pcn191

Wang, Y., Cong, Q. Q., Lan, Y. F., Geng, C., Li, X. D., Liang, Y. C., ... Li, X. D. (2014). Development of new potato virus $X$-based vectors for gene over-expression and gene silencing assay. Virus Research, 191, 62-69. http://dx.doi.org/10.1016/j.virusres.2014.07.018

Zhang, H. B., Jordheimb, M., Lewisa, D. H., Arathoona, S., Andersenb, Ø. M., \& Davies, K. M. (2014). Anthocyanins and their differential accumulation in the floral and vegetative tissues of a shrub species (Rhabdothamnus solandri A. Cunn). Scientia Horticulturae, 165, 29-35. http://dx.doi.org/10.1016/j.scienta.2013.10.032

Zhou, T., Zhang, H., Lai, T. F., Qin, C., Shi, N. N., Wang, H. Z., ... Hong, Y. G. (2012). Virus-induced gene complementation reveals a transcription factor network in modulation of tomato fruit ripening. Scientific Reports, 2, 836. http://dx.doi.org/10.1038/srep00836 


\section{Appendix}

Appendix 1. Primers used for vector construction and qRT-PCR

\begin{tabular}{|c|c|c|c|}
\hline Name & NCBI accession & Forward primer ( $5^{\prime}$ to $\left.3^{\prime}\right)$ & Reverse primer ( $5^{\prime}$ to $\left.3^{\prime}\right)$ \\
\hline & & \multicolumn{2}{|c|}{ Vector construction } \\
\hline$m L e S P L-C N R$ & XM_004232855 & CCTCACATCGATTAGGAAACTAACAAATGGGAAGGGA & GATGCTCGGCCGTCAGCCCAAATTTTCTCCATGAGAG \\
\hline \multirow[t]{2}{*}{ PVX Sequencing } & M95516 & CAGTGTTGGCTTGCAAACTAG & ACTATGGCACGGGCTGTACTAAAG \\
\hline & & \multicolumn{2}{|c|}{ Transcription factor genes relate to fruit ripening } \\
\hline$Q 18 S$ & KJ813746 & CGGCTACCACATCCAAGGAAGG & GAGCTGGAATTACCGCGGCTG \\
\hline QLeSPL-CNR & XM_004232855 & GCTCTCTATCTTCTGTCAATTCCCG & TCGAATACTAGCAGACAGTGCCAAC \\
\hline QSIAP2a & NM_001247523 & GGAGTATGAATCCGATGAAGGT & CGATTCCAAATTGTGGTCTT \\
\hline QLeHBI & NM_001247367 & CTACGACGAGCAGTCACCG & GGAACCATACAGCCACCT \\
\hline QSIMADSI & NM_001247451 & GTGTAGCTGGATTTCCACTTCG & GCCGCTGCATTCACCTCAT \\
\hline$Q S I M Y B$ & NM_001247472 & TAACGAGCAATAATGTAGGGAATAG & GTAAGTTAGTGTCAGTATCGTCCCA \\
\hline QLeNOR & NM_001247723 & AGAGAACGATGCATGGAGGTTTGT & ACTGGCTCAGGAAATTGGCAATGG \\
\hline QSITAGL1 & NM_001247258 & GCAATAACTCCCTGCCTGTA & AGATGAAGAGCCTTGACCC \\
\hline QLeTDR4 & NM_001247244 & ACTGGACTCTCCTCACCTTGGGG & AGCTGCACCTTGCTGCTGTGA \\
\hline \multirow[t]{2}{*}{ QLeRIN } & NM_001247741 & AAGGAACCCAAACTTCATCAG & TTGTCCCAAATCCTCACCTA \\
\hline & & \multicolumn{2}{|c|}{ Genes related to ethylene biosynthesis } \\
\hline QLeACS1 & XM_004253377 & GTGCTTCAAACAAAGGGAC & GTCCTAACCAAAGGCGAAT \\
\hline QLeACS2 & NM_001247249 & GTAGGTGTTGAGAAAAGTGGAG & GTCTTAACGAACTAATGGTGAGG \\
\hline QLeACS3 & NM_001247097 & CATCTCTGAAAATCAGAAGAGGCT & CCATAAGTCCATTTCAGCGTCA \\
\hline QLeACS4 & M88487 & AAATCTCCACCTTCACTAACGAAC & CCTAAGTCCTTGGAAAGACTAGACAC \\
\hline QLeACS6 & NM_001247235 & CAATACTGTAGAACAAGGAGC & GGTACTCAGTGAAATAGTCGAC \\
\hline QLeACOI & HQ322499 & CACTAACGGGAAGTACAAGAG & CTGCATCACTTCCTGGATTGTA \\
\hline QLeACO2 & HQ322499 & CAACTCCTCAAAGACGGTCG & GTCCCGTCTTTTTGTGCGAT \\
\hline QLeACO3 & Z54199 & ATGGGACTCGGATGTCACTAGC & CTTCCATAGCCTTCATTGCTTC \\
\hline QLeACO4 & NM_001246938 & CTGTCAACTTAGGTCCAATA & GCTCACTACCAAACAACAG \\
\hline
\end{tabular}

Appendix 2. Abbreviations used

B, breaker; Cnr, Colourless non-ripening; DPA, days post anthesis; IMG, immature green; MG, mature green; PVX, Potato virus X; RAG, ripening-associated gene; qRT-PCR: quantitative real-time polymerase chain reaction; VIGS, virus-induced gene silencing.

\section{Copyrights}

Copyright for this article is retained by the author(s), with first publication rights granted to the journal.

This is an open-access article distributed under the terms and conditions of the Creative Commons Attribution license (http://creativecommons.org/licenses/by/3.0/). 